\title{
Role of imaging in the diagnosis and management of patients with cardiac amyloidosis: State of the art review and focus on emerging nuclear techniques
}

\author{
Wael A. AlJaroudi, MD, FACC, FAHA, FESC, FASE, FASNC, ${ }^{a}$ Milind Y. Desai, MD, ${ }^{b}$ \\ W. H. Wilson Tang, MD, ${ }^{b}$ Dermot Phelan, MB, BCH, PhD, ${ }^{b}$ Manuel D. Cerqueira, \\ $M D,{ }^{b}$ and Wael A. Jaber, $M D^{b}$
}

\begin{abstract}
Amyloidosis is an infiltrative disease characterized by deposition of amyloid fibrils within the extracellular tissue of one or multiple organs. Involvement of the heart, cardiac amyloidosis, is recognized as a common cause of restrictive cardiomyopathy and heart failure. The two major types of cardiac amyloidosis are cardiac amyloid light-chain (AL) and transthyretin-related cardiac amyloidosis (ATTR, mutant and wild types) (Nat Rev Cardiol 2010;7:398-408). While early recognition of cardiac amyloidosis is of major clinical importance, so is the ability to differentiate between subtypes. Indeed, both prognosis and therapeutic options vary drastically depending on the subtype. While endomyocardial biopsy with immunostaining is considered the gold standard, advances in imaging provide an attractive non-invasive alternative. Currently, electrocardiography, echocardiography, and cardiac magnetic resonance imaging are all used in the evaluation of cardiac amyloidosis with varying diagnostic and prognostic accuracy. Yet, none of these modalities can effectively differentiate the cardiac amyloid subtypes. Recent data with ${ }^{99 m} \mathrm{Tc}$-phosphate derivatives, previously used as bone seeking radioactive tracers, have shown promising results; these radiotracers selectively bind ATTR, but not AL subtype, and can differentiate subtypes with high diagnostic accuracy. This review will initially present the non-radionuclide imaging techniques and then focus on the radionuclide imaging techniques, particularly ${ }^{99 \mathrm{~m}} \mathrm{Tc}$-DPD and ${ }^{{ }^{99} \mathrm{~m}} \mathrm{Tc}-\mathrm{PYP}$, mechanism of action, performance and interpretation of the study, diagnostic accuracy, prognostic value, future clinical perspective, and outlook.
\end{abstract}

Key Words: Cardiac amyloidosis $\cdot$ noninvasive multimodality imaging $\cdot$ transthyretin amyloid

\section{INTRODUCTION}

Amyloidosis is an infiltrative disease characterized by extracellular deposition of fibrillary protein into one (localized) or multiple organs (diffuse or systemic).

\footnotetext{
From the Division of Cardiovascular Medicine and Imaging, ${ }^{\text {a }}$ American University of Beirut Medical Center, Beirut, Lebanon; and Division of Cardiovascular Medicine, Heart and Vascular Institute, ${ }^{\mathrm{b}}$ Cleveland Clinic, Cleveland, $\mathrm{OH}$.

Funds None.

Reprint requests: Wael A. AlJaroudi, MD, FACC, FAHA, FESC, FASE, FASNC, Division of Cardiovascular Medicine and Imaging, American University of Beirut Medical Center, Beirut, Lebanon; wa53@aub.edu.lb.

J Nucl Cardiol 2014;21:271-83.

$1071-3581 / \$ 34.00$

Copyright (c) 2013 American Society of Nuclear Cardiology.

doi:10.1007/s12350-013-9800-5
}

Involvement of the heart (cardiac amyloidosis) is being increasingly recognized as an important cause of restrictive cardiomyopathy and congestive heart failure. The two major types of cardiac amyloidosis are: (1) cardiac amyloid light-chain (AL), and (2) transthyretin-related cardiac amyloidosis (ATTR). ${ }^{1}$ In the AL subtype, the fibril proteins are composed of immunoglobulin light chains that are produced by monoclonal plasma cells in the bone marrow. The ATTR subtype, on the other hand, is due to an autosomal-dominant mutation (more than 80-100 known mutations, also known as mutant or familial cardiac amyloidosis) or wild-type variant (also known as senile systemic amyloidosis). The mutation causes destabilization of the transthyretin protein (normally stable soluble tetramer) into misfolded monomers or dimers that form fibril sheets and get deposited into the heart and other organs. ${ }^{1}$

While both subtypes can involve the heart among other organs, the two subtypes carry different prognosis 
and are targeted by different treatment options. For example, the AL subtype is associated with greater than $50 \%$ mortality within 6 months after the diagnosis, while the ATTR subtype has a more favorable prognosis of 3-5 years, 98\%-100\% 2-year survival, and preferentially better survival with the wild-type variant. ${ }^{2}$

Chemotherapy targeting the plasma cells is the treatment option for AL. Treatment options for ATTR include orthotopic liver transplantation (familial ATTR only) and, more recently, agents designed to stabilize the TTR tetramer (diflunisal, tafamadis), ${ }^{3}$ and reduce de novo TTR synthesize in the liver using RNA interference therapy. ${ }^{4}$ Therefore, differentiating the type of cardiac amyloidosis (AL vs ATTR) is crucial in guiding patient care. Furthermore, differentiating ATTR into mutant vs wild-type is also important since the former is inherited (autosomal dominant); determining the mutation and performing genetic testing on the family are recommended and standard of care.

Although endomyocardial biopsy with immunohistochemistry staining is the gold standard for the diagnosis, several imaging modalities have been used as non-invasive alternatives. While electrocardiogram, echocardiography, and cardiac magnetic resonance imaging (CMR) have been used with various diagnostic accuracy (Table 1), none of them can differentiate the type of cardiac amyloidosis. In the last decade, however, there have been increasing data on the role of nuclear tracers with single photon emission computed tomography (SPECT) and more recently with positron emission tomography (PET) on early identification of cardiac amyloidosis, and more importantly differentiating ATTR from AL subtypes. Two tracers have gained popularity and clinical use; (1) ${ }^{99 \mathrm{~m}} \mathrm{Tc}-\mathrm{DPD}$ which is used mainly in Europe and Asia but not is FDA approved for use in the United States, and (2) ${ }^{99 m} \mathrm{Tc}$ PYP which is used in the United States.

The aim of this review is to present initially the nonradionuclide imaging techniques used for the diagnosis of cardiac amyloidosis (ECG, echocardiography, CMR), and then focus on the radionuclide techniques, particularly ${ }^{99 m}$ Tc-DPD and ${ }^{99 m}$ Tc-PYP, describing the mechanism of action, performance, and interpretation of nuclear studies including diagnostic accuracy, prognostic value, and future clinical perspectives.

\section{GOLD STANDARD FOR DIAGNOSIS: BIOPSY WITH IMMUNOHISTOCHEMISTRY}

The gold standard for the diagnosis of cardiac amyloidosis is tissue biopsy. Fat-pad and rectal biopsy have been used with various sensitivities (less sensitive overall in ATTR) to diagnose the presence of infiltrative amyloidosis and avoid endomyocardial biopsy. ${ }^{5}$ The latter, however, has a sensitivity close to $100 \%$ although associated with low-risk of procedural complication. ${ }^{6}$ The typical appearance of amyloid is viewed with Congo red stain that produces an apple-green birefringence under polarized light microscopy, and more commonly now Thioflavin S stain. The next step is to use immunohistochemistry stain with antibodies to immunoglobulin light chain and to amyloid fibril proteins to distinguish AL vs ATTR subtypes, respectively (Figure 1). Mass spectroscopy and laser microdissection can also be used with high diagnostic accuracy although not widely available or popular. ${ }^{7}$

\section{NON-NUCLEAR TECHNIQUES}

While myocardial biopsy is the gold standard, the complementary role and impact of ECG, echocardiography, and CMR in diagnosing cardiac amyloidosis have been recently highlighted. ${ }^{8}$

\section{Electrocardiogram (ECG): Diagnostic Criteria and Limitations}

The classical feature on an ECG that triggers the suspicion and workup for cardiac amyloidosis is the presence of new low voltage. ${ }^{9}$ Unlike AL, where low voltage is seen in the majority of cases, ${ }^{10}$ less than a quarter of patients with ATTR subtype (even less depending on the mutation) have low-voltage. ${ }^{11,12}$ The main limitation of low-voltage criteria is the low sensitivity and specificity in the diagnosis of amyloidosis, not to mention differentiating subtypes. This is in part due to a large overlap with other conditions; in particular obesity, pectus carinatum, and chronic obstructive lung disease. When accounting for LV mass, a relative low voltage (voltage to mass ratio) is more sensitive in detecting cardiac amyloidosis. ${ }^{13}$ Still, the presence of low voltage depends on the extent and duration of the disease. ${ }^{14}$ Recent data from a single center showed improved diagnostic accuracy of 12-lead ECG using more sophisticated criteria than standard low-voltage. ${ }^{15}$ In particular, a corrected QT duration $>440 \mathrm{~ms}$ and a Sokolow-Lyon index $\leq 1.5 \mathrm{~mm}\left(\mathrm{~S}\right.$ in $\mathrm{V}_{1}+\mathrm{R}$ in $\mathrm{V}_{5}$ or $\mathrm{V}_{6}$ or $\mathrm{R}$ in $\left.\mathrm{aVL}\right)$ were found to have a sensitivity and specificity of $85 \%$ and $100 \%$, respectively. Also, a novel index ([PQ interval minus P-wave duration in lead II multiplied by corrected QT duration]/Sokolow-Lyon index) was shown to be highly diagnostic for the differentiation of amyloidosis (area under the curve 0.92) from other disease. However, there was no distinction of the subtype of amyloidosis based on any of these criteria. ${ }^{15}$ Fragmented QRS on an ECG has been recently described in cardiac amyloidosis without distinguishing subtypes. ${ }^{16}$ Its presence is likely related to cardiomyopathy, scar, and fibrosis, although not 
Table 1. Non-nuclear imaging tests in cardiac amyloidosis

Non-nuclear

imaging test

Immunohistochemistry

Electrocardiogram

Echocardiogram

Cardiac MRI

\section{Characteristics}

Biopsy with staining is the gold standard

Proper immunohistochemistry can differentiate the subtypes

Low voltage has a very low sensitivity for ATTR, and overlap with other disease

Fragmented QRS: low sensitivity and specificity

New criteria

Corrected QT duration $>440 \mathrm{~ms}$ and a Sokolow-Lyon index $\leq 1.5 \mathrm{mV}$ have a

sensitivity of $85 \%$ and specificity $100 \%$ [PQ interval minus P-wave duration in lead II

multiplied by corrected QT duration]/Sokolow-Lyon index: AUC 0.92

Has prognostic value

Most data is limited to AL subtype

Speckle tracking appearance: harmonic imaging has reduced its positive predictive value

Increased LV wall thickness (ATTR > AL); overlap with other infiltrative disease such as hypertrophic CM, severe LVH, Fabry's disease

Increased interatrial septal thickness, pleural and pericardial effusion, valve thickening (non-specific)

Apical sparring on Bull's eye plot of Global Longitudinal strain: SN 96\%, SP 88\% (in patients without (AD). Does not differentiate AL vs ATTR

Promising role for strain for prognostication beyond traditional markers

Diffuse enhancement of the myocardium (ATTR $>A L$ )

Right ventricular enhancement in ATTR and less in AL

Abnormal T1 kinetics (visual T1 mapping).

Abnormal T2 kinetics: T2 ratio (myocardium/skeletal muscle) $<1.5$

Underestimation of the degree of amyloid involvement due to difficulty nulling the myocardium

Does not differentiate AL vs ATTR

Mixed prognostic data with LGE

$\mathrm{T} 1$ and T2 kinetics seem to provide more robust prognostic data

New promising data with equilibrium contrast to measure extracellular volume fraction and quantify amyloid burden

Adopted from Refs. ${ }^{4-45}$

very sensitive or specific given large overlap with other infiltrative disease and ischemic cardiomyopathy, especially in the elderly population.

Other common ECG features of cardiac amyloidosis include intraventricular conduction delays, blocks, and arrhythmias, ${ }^{17}$ more so with ATTR as compared to AL subtypes, and decreased heart rate variability particularly with AL and in some mutations of the ATTR subtypes that are associated with various degrees of autonomic dysfunction. ${ }^{18}$

\section{Prognostic Value}

The presence of low voltage is associated with worse outcome ${ }^{19}$ with various areas-under the curves depending on which voltage criteria are used. Fragmented QRS is also associated with worse outcome (HR 1.572 death hazard ratio [1.03-2.40], $P=.038) .{ }^{16}$

The presence of intraventricular conduction delays or blocks, particularly as they progress over time, reflect worsening of the disease and involvement of the conduction system and high likelihood of requiring a permanent pacemaker, but also higher mortality in AL subtype. ${ }^{20}$ Reduced heart rate variability on a 24 hour Holter predicts high short-term mortality in AL, but limited data in ATTR subtypes on mortality is currently available. ${ }^{18}$

Despite its widespread availability and low cost, ECG has limited overall diagnostic accuracy and data on accurately differentiating amyloid subtypes. New 


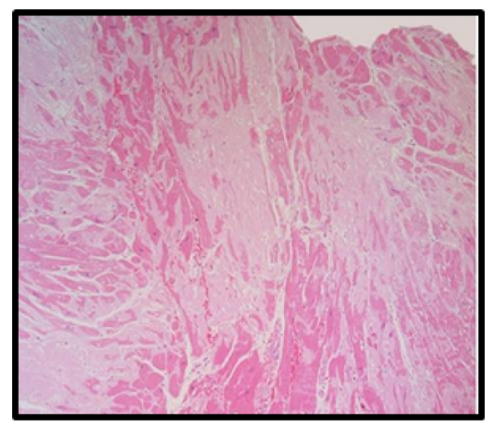

$H \& E$

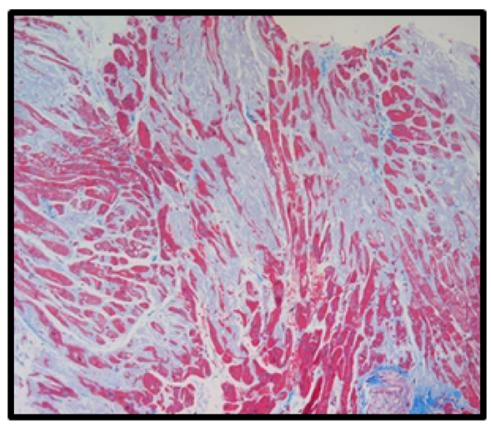

Masson's Trichome

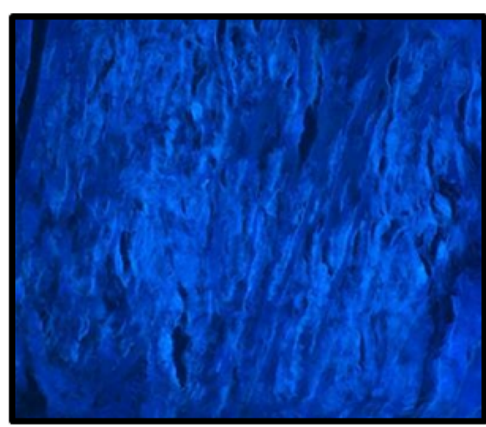

Thioflavin S

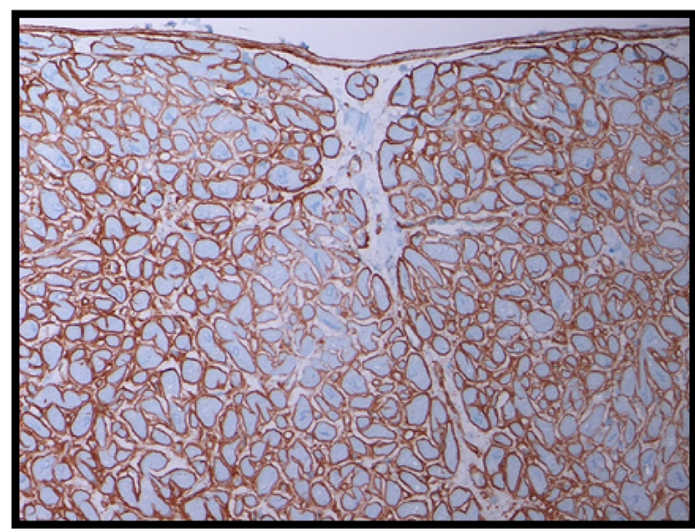

$\lambda$ chain antibody

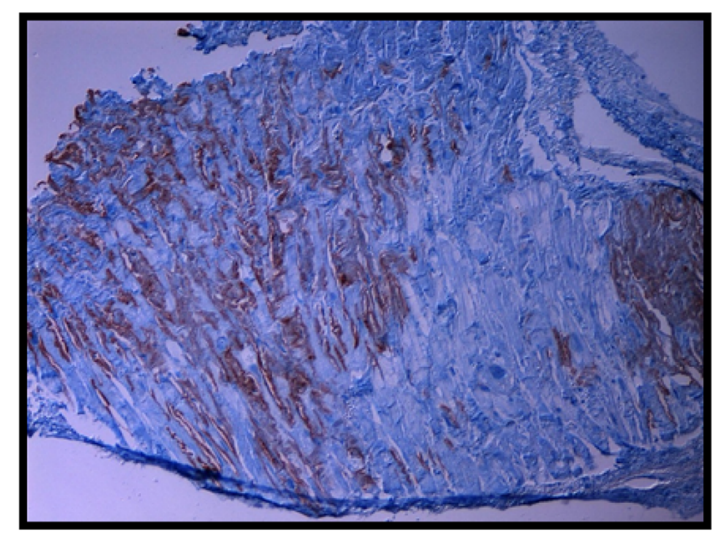

TTR antibody

Figure 1. Endomyocardial biopsy with different staining of cardiac amyloidosis. Endomyocardial biopsy and different pathology specimen showing evidence of cardiac amyloidosis using H\&E, Masson's Trichome, and Thioflavin S stains (upper row). Immunohistochemistry was then performed using $\lambda$ chain antibody (detects AL amyloidosis) and transthyretin antibody to detect ATTR in different patients (lower row).

sophisticated criteria seem promising and need prospective validation in future studies.

\section{Echocardiography}

\section{Criteria for diagnosis and limita-}

tions. There are a constellation of findings seen on an echocardiogram that may trigger the suspicion of cardiac amyloidosis. In particular, there is significant increase, most often symmetrical, in left ventricular (LV) wall thickness. It is worthwhile stressing that the correct terminology for describing the increase in $\mathrm{LV}$ mass is increased wall thickness rather than LV hypertrophy; the latter is secondary to myocyte hypertrophy, while in amyloidosis there is increased extracellular deposition of amyloid protein without myocyte hypertrophy leading to wall thickening. The appearance of the LV wall has been classically described as "sparkling or speckled appearance." In addition, there is thickening of the right ventricular wall, valve leaflets and interatrial septum, and often pleural and pericardial effusions. Diastolic function is often impaired with restrictive filling pattern in the advanced stages of the disease with concomitant severe dilation of the atria, and not uncommonly atrial thrombi $(27 \%$ in one case series, one quarter in the right atrium). ${ }^{21}$

However, there are several limitations to traditional echocardiography in the diagnosis of cardiac amyloidosis. First, "speckled appearance" alone is not diagnostic of cardiac amyloidosis, since harmonic imaging, glycogen storage disease, hypertrophic cardiomyopathy, and end-stage renal disease produce similar echocardiographic appearance. ${ }^{22}$ Second, cardiac amyloidosis is a progressive disease without many of these findings, particularly in the early stage of the disease process. ${ }^{23}$ Indeed, patients with confirmed diagnosis of cardiac amyloidosis might present with grade I (mild) diastolic dysfunction and be asymptomatic; in such early cases, significant wall thickening, and effusions might not be evident. Lastly and more importantly, echocardiography cannot distinguish the subtypes of amyloidosis. While several studies showed relatively greater LV wall thickness and more involvement of the right ventricle in ATTR as compared to AL, there are no cut-off values 

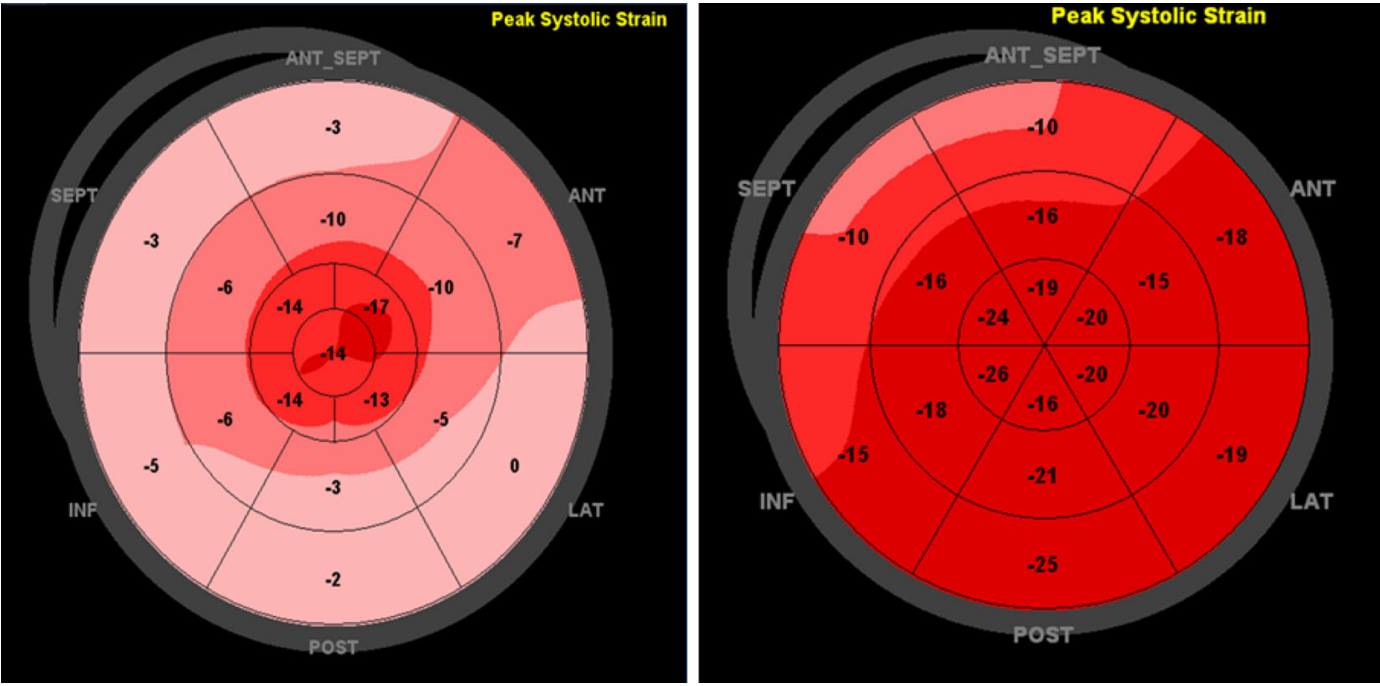

Figure 2. Global longitudinal strain: Bull's Eye Map. Global longitudinal strains with Bull's eye map were performed on two patients with increased LV wall thickness, left ventricular ejection fraction $55 \%$, and congestive heart failure with restrictive diastolic dysfunction. Both patients had abnormal longitudinal strain. However, one patient had apical sparing pattern (left panel) which is very characteristic of cardiac amyloidosis (confirmed with tissue biopsy), while the second one had decreased strain in the basal septum and anteroseptum (right panel) that was suggestive of hypertrophic cardiomyopathy (confirmed with cardiac MRI).

with enough diagnostic accuracy for clinical application. ${ }^{3}$ Combining echocardiographic and ECG testing, however, was shown to improve diagnostic accuracy of the test, but still without differentiating subtypes. ${ }^{24}$

Role of strain imaging. There have been increasing data on the role of strain imaging in cardiac amyloidosis with both longitudinal and radial strains being reduced in the disease state. ${ }^{25,26}$ The clinical use of such data, however, is difficult to apply clinically given the overlap of diseases that are also associated with reduced global strain. Recently, however, Phelan et $\mathrm{al}^{27}$ described a characteristic regional pattern of longitudinal strain easily identified on strain polar maps or "Bull's eye" plots; patients with cardiac amyloidosis typically display marked decrease in longitudinal strain in the basal- and mid-wall segments with relative apical sparring of longitudinal strain. This is in contradistinction to hypertrophic cardiomyopathy, where there is preferential decrease in longitudinal strain at the site of greatest hypertrophy. This pattern was integrated into a relative apical longitudinal strain formula (average apical longitudinal strain/(average basal + mid longitudinal strain); a score of $>1$ was associated with an impressive $93 \%$ sensitivity and $82 \%$ specificity (area under curve 0.94) for the diagnosis of cardiac amyloidosis ${ }^{27}$ (Figure 2). However, it is worth mentioning that patients with known coronary artery disease were excluded from the study. In addition, both AL and ATTR were grouped together and it is less likely than strain pattern can differentiate the different subtypes.
Hence, strain imaging in patients with restrictive cardiomyopathy or other features suggestive of cardiac amyloidosis has become standard of care in our laboratories. Furthermore, new data have shown promising role of right ventricular strain in the diagnosis of AL (no data on ATTR yet), ${ }^{28}$ but this technique has not been adopted in clinical practice yet.

Prognosis. The prognostic value of echocardiography in patients with cardiac amyloidosis was first shown couple of decades ago by Klein et $\mathrm{al}^{29}$ using mitral inflow pattern; restrictive filling was associated with increased mortality. Since then, a number of echocardiographicderived parameters such as LV wall thickness, ejection fraction, right ventricular size, and myocardial performance index have been associated with outcomes. ${ }^{30}$ Increased left atrial size, a marker of diastolic dysfunction, was also associated with worse outcomes. ${ }^{31}$ Given the progressive nature of the disease, Kristen et $\mathrm{al}^{32}$ demonstrated rapid progression of increased LV wall thickness predicted mortality in AL. Furthermore, abnormal ejection time $<240 \mathrm{~ms}$ (a marker of early systolic dysfunction) has a sensitivity of $73 \%$ and a specificity of $90 \%$ in predicting 1 year cardiac mortality. ${ }^{33}$ However, data from Cleveland Clinic showed that only New York Heart Association class was associated with worse outcomes after adjusting for ECG, EF, and diastolic dysfunction. ${ }^{34}$

Recently, left and right ventricular strains have proven to be even more powerful prognostic markers beyond traditional risk factors. Indeed, data from Mayo 


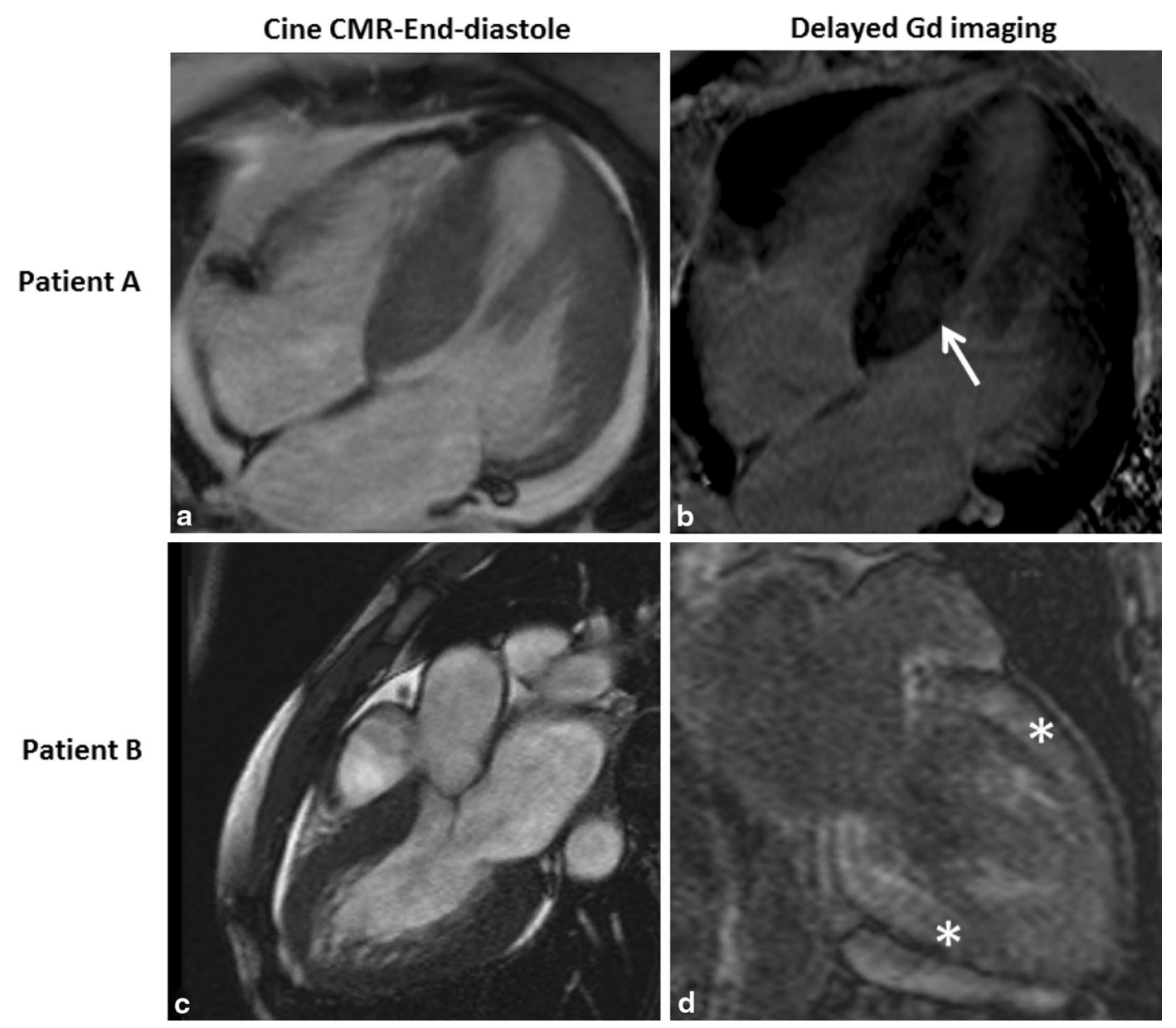

Figure 3. Cardiac MRI with late gadolinium enhancement. CMR was performed for two patients that had increased wall thickness on Cine images $(\mathbf{A}, \mathbf{C})$. On delayed $\mathrm{Gd}$ enhancement however, patient A had late Gd enhancement in the septum (B arrow), a pattern suggestive of hypertrophic cardiomyopathy; while patient $\mathrm{B}$ had diffuse LGE with difficulty to null the myocardium (D asterisk), a pattern consistent with cardiac amyloidosis.

clinic showed that peak longitudinal systolic strain of the basal anteroseptal segment less negative than or equal to $-7.5 \%$ was an independent predictor of death after adjusting for traditional risk factors (HR 1.05, $P=.02) .{ }^{33}$ Data from Boston also showed than mean LV basal strain was the only independent predictor of both cardiac and all-cause mortality in AL patients. ${ }^{35}$ Similarly, Buss et $\mathrm{al}^{36}$ showed that reduced global longitudinal strain was an independent predictor of survival with incremental value in one of the largest studies. Lastly, abnormal right ventricular strain is also an independent predictor of death beyond E/A filling pattern or diastology. However, all of the cohorts consisted of patients with AL subtype, and with limited data on ATTR.

CMR: Criteria for diagnosis and limitations. Late gadolinium delayed enhancement (LGE) CMR has diagnostic value in cardiac amyloidosis. In this disease, there is interstitial expansion from the amyloid deposit that avidly picks up and retains $\mathrm{Gd}$ leading to signal enhancement of the tissue and fast blood pool washout. Global transmural or diffuse subendocardial LGE can detect the disease early on without significant increase in LV wall thickness, and correlate with disease severity ${ }^{37-39}$ (Figure 3).

In a recent study, Austin et $\mathrm{al}^{23}$ showed that LGECMR had a sensitivity of $88 \%$, specificity $95 \%$, positive predictive value of $93 \%$, and negative predictive value of $90 \%$ in patients with biopsy proven amyloidosis. However, there are several limitations to LGE-CMR: (1) patchy myocardial involvement is not uncommon and can be easily missed; (2) the diffuse nature of LGE presents a challenge for conventional CMR as normal reference myocardium-used to provide context for setting pulse sequence parameters and for visual interpretation-may be absent; as such, CMR can visually 
underestimate the disease burden as compared to ${ }^{99 \mathrm{~m}} \mathrm{Tc}$ diphosphonate nuclear imaging. ${ }^{40}$

Visual T1-mapping technique is an alternative technique that allows detection of abnormal Gd kinetics in the myocardial tissue; early nulling of the myocardium before the blood pool on inversion recovery reflects an abnormally low $\mathrm{T} 1$ of the myocardium due to significant Gd uptake in the extracellular space and is highly suggestive of the presence of infiltrative cardiac amyloidosis. This technique provides a semiobjective way of determining the presence of abnormal $\mathrm{Gd}$ kinetics and cardiac amyloidosis. Using receiver-operating characteristic analysis, a value of $1,020 \mathrm{~ms}$ on noncontrast T1 mapping has $92 \%$ accuracy for identifying either possible or definite AL amyloid cardiomyopathy. ${ }^{41}$ Recent data have shown promising role for equilibrium contrast CMR for quantification of extracellular volume fraction as a more robust method that correlates with amyloid burden, and hence quantify it objectively. ${ }^{42,43}$

More recently, alteration of $\mathrm{T} 2$ kinetics with decreased T2 myocardium/skeletal muscle ratio, has been described in cardiac amyloidosis, in part due to pronounced local field inhomogeneity. ${ }^{44}$ None of the CMR techniques, however, can differentiate subtypes of cardiac amyloidosis. One characteristic feature, however, is that ATTR subtype almost always has LGE of the right ventricle, while almost a third of patients with AL do not. ${ }^{45}$

Prognostic value. There have been conflicting data regarding prognostic value of LGE CMR in cardiac amyloidosis. ${ }^{23,39,46,47}$ While some studies failed to establish prognostic value of LGE, other studies have shown that LGE was the only predictor of 1-year mortality $(P=.03)$ beyond ECG and diastology. ${ }^{23} \mathrm{~T} 1$ mapping, on the other hand, seems more robust and a better predictor of outcomes with $90 \%$ accuracy, in part due to its superior discriminatory power. ${ }^{39}$ Similar to T1 kinetics, T2 kinetics with a T2 (myocardium/skeletal muscle) ratio $<1.5$ was shown to be the only independent predictor of death in 36 patients with various subtypes of cardiac amyloidosis (2 with ATTR and 31 with AL). ${ }^{44}$ All the studies, however, were of small sample size with few events and inadequate power to adjust for all potential confounders.

\section{RADIONUCLIDE TECHNIQUES}

\section{Nuclear Tracers}

Several radiotracers have been tested and utilized with various degrees of success in the diagnosis of cardiac amyloidosis. Each of the radiotracers evaluated for the detection of cardiac amyloidosis has targeted different components altered in the heart: sympathetic innervation, perfusion, metabolism, or amyloid-deposits. ${ }^{48}$ Although more than a dozen radiotracers have been evaluated over the last couple of decades, there are very limited data on most of them (Table 2). ${ }^{49-59}$ Recently, ${ }^{99 m}$ Tc-DPD (technetium-3,3-diphosphono1,2-propanodicarboxylic acid) and ${ }^{99 \mathrm{~m}} \mathrm{Tc}-\mathrm{PYP}$ (technetium pyrophosphate) have shown promises. ${ }^{56,57}$ Their main advantage is avid uptake by ATTR and minimal uptake with the AL subtype, providing one of the best non-invasive ways to differentiate the subtypes of cardiac amyloidosis. The rest of this review will focus on the ${ }^{99 \mathrm{~m}} \mathrm{Tc}$-phosphate derivatives that are the most commonly used and have gained widespread acceptance in the investigation of suspected ATTR.

\section{Mechanism of Action}

The ${ }^{99 \mathrm{~m}} \mathrm{Tc}$-phosphate derivatives were originally developed for bone imaging, but were also observed to accumulate in areas of healing in the context of acute myocardial infarction. Such uptake was observed several days after the acute event and thought to be part of the healing process with deposition in mitochondria where there was calcium overloading. Later, it was discovered that these radiotracers accumulate in the myocardium of patients with cardiac amyloidosis. Although the precise mechanism is not well known, there have been several suggested theories. The first is that high calcium levels in amyloidosis bind to phosphate in the radiotracers. ${ }^{60}$ The preferential binding of ${ }^{99 \mathrm{~m}} \mathrm{Tc}$-phosphate derivatives to ATTR may be due to the fact that transthyretin amyloid fibrils have higher calcium content. Pepys et $\mathrm{al}^{61}$ showed that normal human serum amyloid protein binds different amyloid fibrils in a highly specific calcium-dependent manner.

Another theory of the preferential binding to ATTR relates to the duration over which amyloid deposition has occurred in the affected tissue. In AL patients, fibrils tend to accumulate over a short period of time as compared to a more indolent course in ATTR. ${ }^{56}$

\section{How to Perform the Study: Image Acquisition and Analysis}

${ }^{99 m}$ TC-DPD. The technique has been previously described in detail. ${ }^{40,57}$ Briefly, after administering $740 \mathrm{MBq}$ of ${ }^{99 \mathrm{~m}} \mathrm{Tc}-\mathrm{DPD}$ intravenously, a whole body scan is performed 3 hours later (anterior and posterior projections) using a dual-head gamma camera equipped with low-energy high-resolution collimators. If there is active uptake in the heart, chest SPECT is performed with images acquired using a circular orbit with $360^{\circ}$ rotation, $3^{\circ}$ step and shoot technique, and an acquisition 
Table 2. Nuclear tracers used in imaging cardiac amyloidosis

\begin{tabular}{|c|c|c|c|}
\hline $\begin{array}{l}\text { Nuclear tracers } \\
\text { (Ref.) }\end{array}$ & $\begin{array}{l}\text { Mechanism of } \\
\text { action }\end{array}$ & Characteristics & $\begin{array}{l}\text { Differentiates } \\
\text { ATTR vs AL }\end{array}$ \\
\hline${ }^{123} \mathrm{I}-\mathrm{MIBG}^{49}$ & $\begin{array}{l}\text { Sympathetic cardiac } \\
\text { innervation }\end{array}$ & $\begin{array}{l}\text { Decreased } \mathrm{H} / \mathrm{M} \text { ratio and increased } \\
\text { washout rate reflect sympathetic } \\
\text { cardiac denervation }\end{array}$ & No \\
\hline${ }^{123} \mathrm{I}-\mathrm{BMIPP}{ }^{50}$ & $\begin{array}{l}\text { Fatty acid } \\
\text { Metabolism }\end{array}$ & Very limited role & No \\
\hline${ }^{99 \mathrm{~m}} \mathrm{Tc}(\mathrm{V})-\mathrm{DMSA}{ }^{51}$ & $\begin{array}{l}\text { Metabolism and avid } \\
\text { uptake }\end{array}$ & $\begin{array}{l}\text { Limited role due to physiological uptake } \\
\text { in the blood pool }\end{array}$ & No \\
\hline${ }^{201} \mathrm{Tl}$ redistribution ${ }^{52}$ & Perfusion & $\begin{array}{l}\text { Higher washout rate associated with } \\
\text { amyloidosis } \\
\text { Limited data; non-specific }\end{array}$ & No \\
\hline $\begin{array}{l}\text { Blood pool } \\
\text { ventriculography }\end{array}$ & $\begin{array}{l}\text { Assesses peak filling } \\
\text { rate and time to } \\
\text { peak filling }\end{array}$ & $\begin{array}{l}\text { Can detect features of restrictive } \\
\text { physiology but not specific to cardiac } \\
\text { amyloidosis }\end{array}$ & No \\
\hline${ }^{99 m}$ Tc-Aprotinin ${ }^{51}$ & $\begin{array}{l}\text { Amyloid deposit } \\
\text { (antiproteases) }\end{array}$ & $\begin{array}{l}5 / 5 \text { biopsy proven cases had }+ \text { tracer } \\
\text { uptake } \\
\text { More useful for extra-abdominal uptake }\end{array}$ & No \\
\hline${ }^{99 m} \mathrm{Tc}_{\mathrm{T}-\mathrm{DPD}}{ }^{53,54,57}$ & $\begin{array}{l}\text { Amyloid deposit (high } \\
\text { calcium content) }\end{array}$ & $\begin{array}{l}15 / 15+\text { uptake in ATTR vs } 0 / 10 \text { in } A L \\
\text { Another study: } 1 / 3 \text { of patients with } A L \\
\text { had mild uptake } \\
\text { Has Prognostic value } \\
\text { Not Available in the USA }\end{array}$ & Yes \\
\hline${ }^{99 \mathrm{~m}} \mathrm{Tc}-\mathrm{MDP}^{55}$ & $\begin{array}{l}\text { Amyloid deposit (high } \\
\text { calcium content) }\end{array}$ & $\begin{array}{l}\text { Mixed results likely secondary to } \\
\text { combining patients with AL and ATTR }\end{array}$ & Not well known \\
\hline${ }^{99 \mathrm{~m}} \mathrm{Tc}-\mathrm{PYP}{ }^{56}$ & $\begin{array}{l}\text { Amyloid deposit (high } \\
\text { calcium content) }\end{array}$ & SN $97 \%$, SP $100 \%$, AUC 0.992 & Yes \\
\hline${ }^{67}$ Ga-citrate ${ }^{58}$ & $\begin{array}{l}\text { Unknown mechanism } \\
\text { for deposition }\end{array}$ & $\begin{array}{l}\text { Limited case reports. Less uptake than } \\
99 \mathrm{~m} \text { Tc-PYP. No role in cardiac } \\
\text { amyloidosis }\end{array}$ & Not known \\
\hline${ }^{111}$ In antimyosin ${ }^{50}$ & $\begin{array}{l}\text { Binds to areas of } \\
\text { myocardial necrosis }\end{array}$ & $\begin{array}{l}\text { 7/7 patients had positive uptake } \\
\text { Non-specific } \\
\text { Only } 1 \text { case report }\end{array}$ & No \\
\hline $\begin{array}{l}{ }^{123} \text { I-Serum amyloid } \\
\text { protein }^{59}\end{array}$ & $\begin{array}{l}\text { Labels the amyloid } \\
\text { pool }\end{array}$ & $\begin{array}{l}\text { Not FDA approved. Only used in } 2 \\
\text { European centers } \\
\text { Not suitable for cardiac amyloidosis } \\
\text { due to movement, blood pool } \\
\text { content and lack of fenestrated } \\
\text { endothelium in the myocardium } \\
\text { Detects visceral uptake in AL but not } \\
\text { ATTR }\end{array}$ & No \\
\hline${ }^{11} \mathrm{C}-\mathrm{BF}-227^{66}$ & $\begin{array}{l}\text { Binds to aggregated } \\
\text { amyloid fibrils }\end{array}$ & $\begin{array}{l}\text { First PET tracer to be used } \\
\text { One case report: correctly identified } \\
\text { ATTR deposition in the heart }\end{array}$ & Not known \\
\hline${ }^{11} \mathrm{C}-\mathrm{PIB}{ }^{67}$ & $\begin{array}{l}\text { Binds to amyloid fibrils } \\
\text { of any type }\end{array}$ & $\begin{array}{l}\text { 10/10 patients (ATTR and AL) had uptake } \\
\text { and } 0 / 5 \text { volunteers had uptake }\end{array}$ & No \\
\hline${ }^{18} \mathrm{~F}$ florbetapir ${ }^{68}$ & $\begin{array}{l}\text { Binds to amyloid fibrils } \\
\text { of any type }\end{array}$ & $\begin{array}{l}5 / 5 \text { patients ( } 3 \text { ATTR, } 2 \mathrm{AL} \text { ) had } \\
\text { decreased myocardial washout. } 0 / 2 \\
\text { healthy controls had uptake }\end{array}$ & No \\
\hline
\end{tabular}


time of 25 seconds per frame using a $128 \times 128$ matrix. The data is then reconstructed using ramp filtered back projection with a Hann filter.

${ }^{99 m}$ TC-PYP. After administering $15-25 \mathrm{mCi}$ of ${ }^{99 m}$ Tc-PYP intravenously, whole body planar imaging is performed with a dual-head gamma camera with lowenergy high resolution collimators, 1 hour after the injection and for a total of 8 minutes acquisition or up to 750,000 counts, with the heart in the center if the field of view $(256 \times 256$ matric and 1.46 zoom factor $)$. In the presence of myocardial uptake, SPECT image acquisitions follows with step and shoot technique, 360 rotation, using a $64 \times 64$ matrix and 1.46 zoom. Reconstruction is performed using a Butterworth filter with a cut off of 0.50 and order of 5.0.

Semi-quantitative visual scoring of the cardiac uptake is performed as follows: $0=$ absent cardiac uptake and intense bone uptake; $1=$ mild cardiac uptake $<$ bone uptake; $2=$ moderate cardiac uptake $=$ bone uptake; $3=$ high cardiac uptake $>$ bone uptake. Quantitative assessment using heart retention, and heart to whole body retention, is assessed using counts in the region of interest as previously described. Similarly, mean total and absolute counts are measured after correction for background counts, and the mean counts in the heart region of interest over the mean counts in the contralateral chest is defined as H/CL ratio. ${ }^{40,56,57}$

\section{Diagnostic Accuracy of ${ }^{99 \mathrm{~m}}$ Tc-Derived Phosphate}

${ }^{99 m}$ Tc-PYP imaging was first described as a potential diagnostic test for cardiac amyloidosis in the early 1980s. Although initial reports described increased cardiac uptake in patients with amyloid heart disease ${ }^{62,63}$; later studies found limited sensitivity with positive scans in less than $20 \%$ of patients casting doubt on the diagnostic accuracy of this technique. ${ }^{13,64}$ These early studies, however, were done at a time when precise typing of amyloidosis was not available; hearts with AL-type amyloid do not pick up ${ }^{99 m}$ Tc-PYP as compared to the avid uptake seen in ATTR. The few studies that attempted to differentiation between subtypes were limited to ATTR wild-type patients only, missing the most common ATTR mutant allele in the United States. In addition, there was a lack of a quantitative measure of tracer retention, and SPECT imaging was not commonly used. In view of all these limitations, the technique was not widely used.

Another tracer, ${ }^{99 m}$ Tc-MDP (technetium-methylene diphosphonate) has been employed in several case reports and small studies for the diagnosis of cardiac amyloidosis, but has demonstrated even lower sensitivity than ${ }^{99 \mathrm{~m}}$ Tc-PYP. ${ }^{55}$
Two decades later, the role of radionuclide techniques for cardiac amyloidosis was revived in Europe with a similar tracer, ${ }^{99 \mathrm{~m}} \mathrm{Tc}-\mathrm{DPD}$. In an initial report, cardiac uptake of ${ }^{9 \mathrm{~m}} \mathrm{Tc}-\mathrm{DPD}$ was present in all 15 patients with TTR amyloidosis (ATTR) compared to none of the 10 patients with $\mathrm{AL}$ amyloidosis. ${ }^{57}$ In a larger cohort of 79 patients (45 ATTR and 34 AL) that evaluated tracer retention (calculated by a heart-towhole body ratio $[\mathrm{H} / \mathrm{WB}]$ ), the diagnostic sensitivity remained high although the specificity was lower than previously reported due to unexpected tracer uptake in about one-third of AL patients. ${ }^{53}$ A recent study showed uptake in all 40 patients with echocardiographic evidence of amyloidosis and detected early evidence of disease in 4/23 patients without echocardiographic evidence that was later confirmed by biopsy. ${ }^{54}$ Hence, ${ }^{99} \mathrm{~m}$ Tc-DPD has a very high sensitivity for the detection of ATTR even in the subclinical or early phase. The specificity, however, is more controversial; one study showed $100 \%$ specificity $(0 / 10$ uptake in patients with $\mathrm{AL})^{57}$ as compared to $\approx 70 \%$ in a larger study, where $1 /$ 3 of patients with AL had some uptake. ${ }^{53}$

Since ${ }^{99 m}$ Tc-DPD is not FDA approved in the United States, studies are performed using ${ }^{99 \mathrm{~m}}$ Tc-PYP. Yamamoto et $\mathrm{al}^{65}$ used the "PYP score"' to assess the utility of ${ }^{99 \mathrm{~m}}$ Tc-PYP to evaluate cardiac amyloidosis in 13 subjects with heart failure due to amyloid (1 AL, 3 ATTRm, 8 ATTRwt) and 37 subjects with heart failure due to non-amyloid causes. PYP score, defined as the ratio of myocardial mean counts to ventricular cavity mean counts, had a sensitivity of $84.6 \%$ and specificity of $94.5 \%$ for distinguishing cardiac amyloidosis from non-amyloid causes of heart failure. In a recent study, Bokhari et $\mathrm{al}^{56}$ evaluated the role of ${ }^{99 \mathrm{~m}} \mathrm{Tc}-\mathrm{PYP}$ in 45 patients (12 AL, 16 ATTR wild-type, 17 ATTR mutant type) using semi-quantitative heart/contralateral ratio score. While patients with AL did have some uptake, the visual score was significantly less than patients with ATTR. A H/CL > 1.5 was associated with $97 \%$ sensitivity and $100 \%$ specificity in differentiating ATTR vs AL. The importance of this study is that although patients with AL can still have some tracer uptake, a quantitative score can differentiate ATTR from AL with almost $100 \%$ specificity. Therefore, radionuclide tracer imaging not only detects ATTR, but can differentiate it from AL with high degree of certainty (Figure 4).

There are no data that compare ${ }^{99 \mathrm{~m}} \mathrm{Tc}-\mathrm{DPD}$ vs ${ }^{99}$ Tc-PYP. ${ }^{99 m}$ Tc-DPD is more sensitive than echocardiography in diagnosing early disease, and can differentiate subtypes, while echocardiography does not. There is one study that compared ${ }^{99 \mathrm{~m}}$ Tc-DPD vs CMR; CMR underestimated the degree of amyloid involvement compared to ${ }^{99 \mathrm{~m}} \mathrm{Tc}-\mathrm{DPD}$, in part due to the 


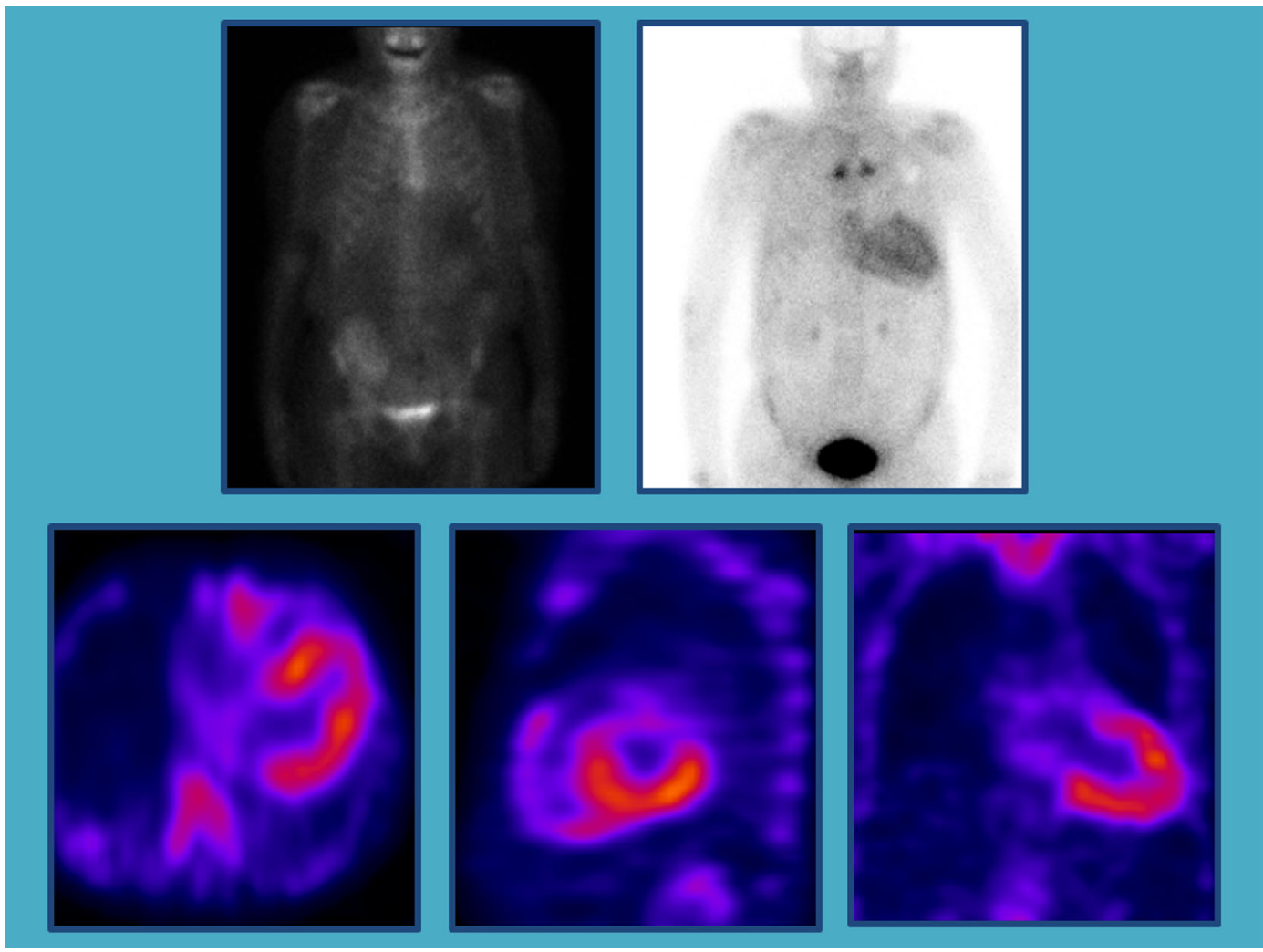

Figure 4. Radionuclide imaging with ${ }^{99 \mathrm{~m}} \mathrm{Tc}-\mathrm{PYP}$ in patients with cardiac amyloidosis. ${ }^{99 \mathrm{~m}} \mathrm{Tc}-\mathrm{PYP}$ planar imaging was performed in two patients with suspected cardiac amyloidosis based on clinical and echocardiographic data. The first patient had almost no uptake (upper row, left panel) and underwent biopsy confirming AL subtype. The second patient had significant uptake (upper row, right panel); SPECT imaging was then performed which showed increased tracer uptake in the heart (axial, sagittal and coronal views) (lower row, respectively) consistent with ATTR subtype. Biopsy was not performed.

limitation of the technique and difficulty nulling the myocardium ${ }^{40}$.

The role of PET imaging in the diagnosis of cardiac amyloidosis has been evaluated in one case report in 2012 using ${ }^{11}$ C-BF-227, ${ }^{66}$ and recently two studies using new tracers: $N$-[methyl-(11)C]2-(4'-methylamino-phenyl)-6-hydroxybenzothiazole ((11)C-PIB) and ${ }^{18} \mathrm{~F}$ florbetapir ${ }^{67,68}$ (Table 2). In both studies, there was selective uptake of the tracer in the myocardium of patients with confirmed cardiac amyloidosis (ATTR and $\mathrm{AL}$ ) but not in healthy volunteers. The importance of these studies is that for the first time these new tracers offer the potential to quantify amyloid burden in the heart beyond a dichotomous (yes/no) or subjective grading scale 0-4. However, none of the tracers is selective for ATTR as they equally bind light chain amyloid deposits. PET has a higher spatial resolution than SPECT, can be fused with CT for better anatomic definition, and therefore is an appealing alternative with promising diagnostic role.

\section{Prognostic Value}

The prognostic value of ${ }^{99 \mathrm{~m}} \mathrm{Tc}$-DPD uptake in the myocardium has been evaluated in a study of 63 patients with ATTR. Heart/whole body retention was used to quantify the degree of myocardial uptake, and was an independent predictor of major adverse cardiovascular events. A H/WB ratio $\geq 7.5$ was associated with the highest event rate. ${ }^{54}$ However, one has to caution the discussion of prognosis as ATTR has better long-term prognosis, especially in senile cases. Also, we do not necessarily know the denominator of patients with amyloid as we have often scan predominantly suspicious cases. There are no prognostic data with ${ }^{99 \mathrm{~m}} \mathrm{Tc}-\mathrm{PYP}$.

\section{Suggested Diagnostic Workflow in Suspected ATTR}

In patients with suspected ATTR (based on clinical presentation, ECG, and echocardiographic findings), 


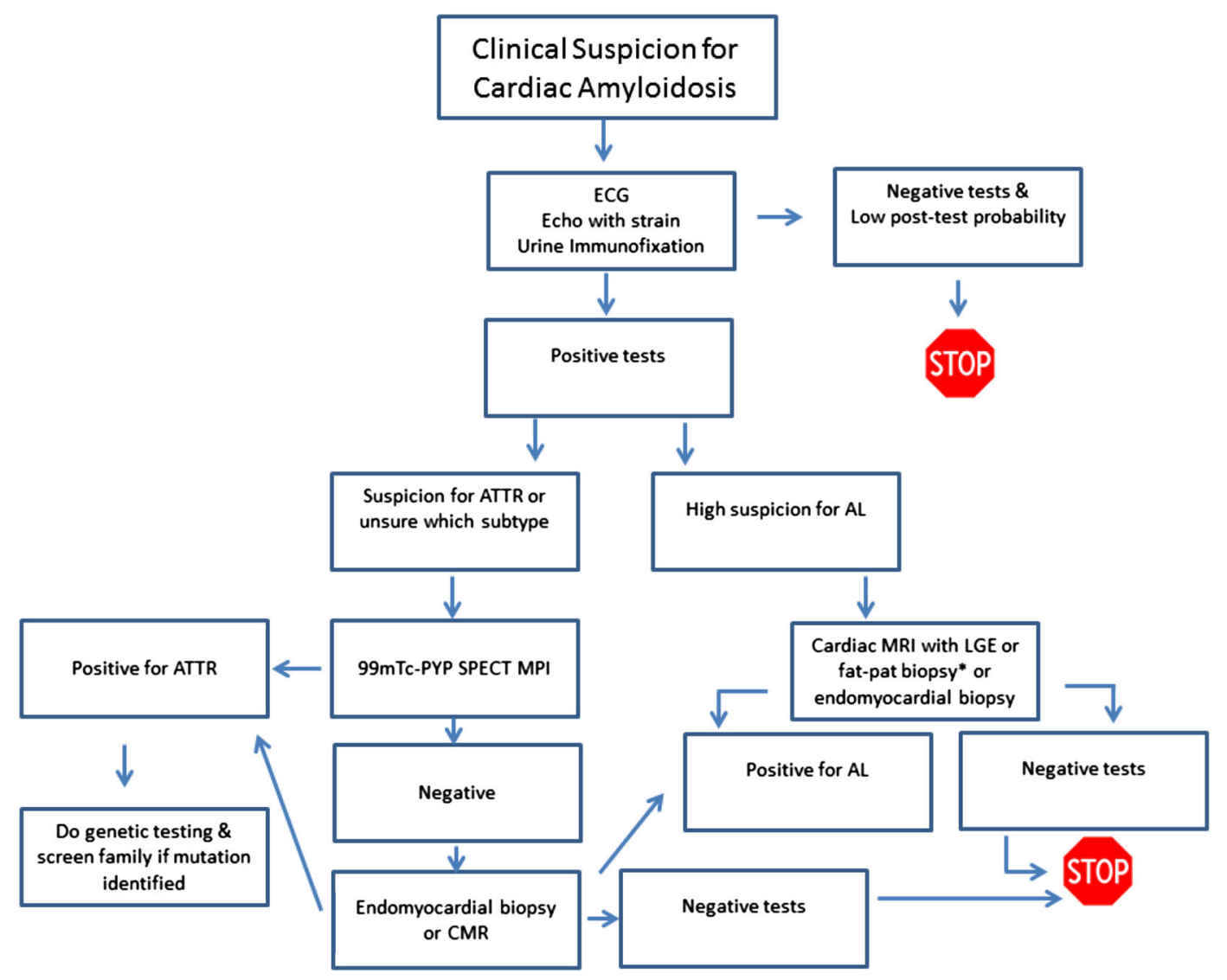

Figure 5. Suggested workflow diagram in the diagnostic workup of cardiac amyloidosis.

radionuclide imaging with either ${ }^{99 \mathrm{~m}} \mathrm{Tc}-\mathrm{DPD}$ or ${ }^{99 \mathrm{~m}} \mathrm{Tc}$ PYP can be used as a non-invasive screening method to differentiate between ATTR vs AL. In the presence of positive myocardial uptake, endomyocardial biopsy may not be needed; genetic testing, however, is helpful to differentiate ATTR mutant from wild type, and if a mutation is identified, family screening should be performed (Figure 5). Such a workflow scheme, however, needs to be tested prospectively for efficiency, diagnostic accuracy, and more importantly costeffectiveness.

\section{Future Studies}

${ }^{99 \mathrm{~m}} \mathrm{Tc}-\mathrm{PYP}$ and ${ }^{99 \mathrm{~m}} \mathrm{Tc}$-DPD possess unique affinity for ATTR, and hence for differentiating subtype of cardiac amyloidosis unlike other non-invasive imaging modalities. Whether this technique is sensitive enough in detecting early disease, and in particular those with positive genotype but negative phenotype, warrants further evaluation. Another potential role for nuclear imaging is monitoring disease progression and more importantly response to therapy. Radiation burden in such serial follow-up needs to be taken into consideration, although the risk of radiation-related complications is likely to be very low given the average age at presentation and the poor prognosis for cardiac amyloidosis. The potential role for new tracers with PET imaging also warrants further investigation.

\section{Conflict of interest}

The authors have indicated that they have no financial conflict of interest.

\section{Disclosures}

None.

\section{References}

1. Rapezzi C, Quarta CC, Riva L, Longhi S, Gallelli I, Lorenzini M, et al. Transthyretin-related amyloidoses and the heart: A clinical overview. Nat Rev Cardiol 2010;7:398-408.

2. Ruberg FL, Maurer MS, Judge DP, Zeldenrust S, Skinner M, Kim AY, et al. Prospective evaluation of the morbidity and mortality of wild-type and v122i mutant transthyretin amyloid cardiomyopathy: 
The transthyretin amyloidosis cardiac study (tracs). Am Heart J 2012; 164:222-8.

3. Dungu JN, Anderson LJ, Whelan CJ, Hawkins PN. Cardiac transthyretin amyloidosis. Heart 2012;98:1546-54.

4. Coelho T, Adams D, Silva A, Lozeron P, Hawkins PN, Mant T, et al. Safety and efficacy of RNAi therapy for transthyretin amyloidosis. N Engl J Med 2013;369:819-29.

5. Kyle RA, Spittell PC, Gertz MA, Li CY, Edwards WD, Olson LJ, et al. The premortem recognition of systemic senile amyloidosis with cardiac involvement. Am J Med 1996;101:395-400.

6. Cooper LT, Baughman KL, Feldman AM, Frustaci A, Jessup M, Kuhl U, et al. The role of endomyocardial biopsy in the management of cardiovascular disease: A scientific statement from the American Heart Association, the American College of Cardiology, and the European Society of Cardiology. Circulation 2007;116:2216-33.

7. Vrana JA, Gamez JD, Madden BJ, Theis JD, Bergen HR 3rd, Dogan A. Classification of amyloidosis by laser microdissection and mass spectrometry-based proteomic analysis in clinical biopsy specimens. Blood 2009;114:4957-9.

8. Piper C, Butz T, Farr M, Faber L, Oldenburg O, Horstkotte D. How to diagnose cardiac amyloidosis early: Impact of ECG, tissue Doppler echocardiography, and myocardial biopsy. Amyloid 2010;17:1-9.

9. Carroll JD, Gaasch WH, McAdam KP. Amyloid cardiomyopathy: Characterization by a distinctive voltage/mass relation. Am J Cardiol 1982;49:9-13.

10. Murtagh B, Hammill SC, Gertz MA, Kyle RA, Tajik AJ, Grogan M. Electrocardiographic findings in primary systemic amyloidosis and biopsy-proven cardiac involvement. Am J Cardiol 2005;95:535-7.

11. Sattianayagam PT, Hahn AF, Whelan CJ, Gibbs SD, Pinney JH, Stangou AJ, et al. Cardiac phenotype and clinical outcome of familial amyloid polyneuropathy associated with transthyretin alanine 60 variant. Eur Heart J 2012;33:1120-7.

12. Buxbaum J, Alexander A, Koziol J, Tagoe C, Fox E, Kitzman D. Significance of the amyloidogenic transthyretin Val 122 Ile allele in African Americans in the Arteriosclerosis Risk in Communities (ARIC) and Cardiovascular Health (CHS) Studies. Am Heart J 2010;159:864-70.

13. Simons M, Isner JM. Assessment of relative sensitivities of noninvasive tests for cardiac amyloidosis in documented cardiac amyloidosis. Am J Cardiol 1992;69:425-7.

14. Dungu J, Sattianayagam PT, Whelan CJ, Gibbs SD, Pinney JH, Banypersad SM, et al. The electrocardiographic features associated with cardiac amyloidosis of variant transthyretin isoleucine 122 type in afro-caribbean patients. Am Heart J 2012;164:72-9.

15. Namdar M, Steffel J, Jetzer S, Schmied C, Hurlimann D, Camici $\mathrm{GG}$, et al. Value of electrocardiogram in the differentiation of hypertensive heart disease, hypertrophic cardiomyopathy, aortic stenosis, amyloidosis, and fabry disease. Am J Cardiol 2012;109:587-93.

16. Perlini S, Salinaro F, Cappelli F, Perfetto F, Bergesio F, Alogna A, et al. Prognostic value of fragmented QRS in cardiac AL amyloidosis. Int J Cardiol 2013;167:2156-61.

17. Granstam SO, Rosengren S, Vedin O, Kero T, Sorensen J, Carlson $\mathrm{K}$, et al. Evaluation of patients with cardiac amyloidosis using echocardiography, ECG and right heart catheterization. Amyloid 2013;20:27-33.

18. Reyners AK, Hazenberg BP, Reitsma WD, Smit AJ. Heart rate variability as a predictor of mortality in patients with AA and AL amyloidosis. Eur Heart J 2002;23:157-61.

19. Mussinelli R, Salinaro F, Alogna A, Boldrini M, Raimondi A, Musca F, et al. Diagnostic and prognostic value of low QRS voltages in cardiac al amyloidosis. Ann Noninvasive Electrocardiol 2013;18:271-80.

20. Boldrini M, Salinaro F, Mussinelli R, Raimondi A, Alogna A, Musca F, et al. Prevalence and prognostic value of conduction disturbances at the time of diagnosis of cardiac al amyloidosis. Ann Noninvasive Electrocardiol 2013;18:327-35.

21. Feng D, Syed IS, Martinez M, Oh JK, Jaffe AS, Grogan M, et al. Intracardiac thrombosis and anticoagulation therapy in cardiac amyloidosis. Circulation 2009;119:2490-7.

22. Olson LJ, Reeder GS, Noller KL, Edwards WD, Howell RR, Michels VV. Cardiac involvement in glycogen storage disease III: Morphologic and biochemical characterization with endomyocardial biopsy. Am J Cardiol 1984;53:980-1.

23. Austin BA, Tang WH, Rodriguez ER, Tan C, Flamm SD, Taylor $\mathrm{DO}$, et al. Delayed hyper-enhancement magnetic resonance imaging provides incremental diagnostic and prognostic utility in suspected cardiac amyloidosis. JACC Cardiovasc Imaging 2009;2:1369-77.

24. Cheng Z, Kang L, Tian Z, Chen W, Guo W, Xu J, et al. Utility of combined indexes of electrocardiography and echocardiography in the diagnosis of biopsy proven primary cardiac amyloidosis. Ann Noninvasive Electrocardiol 2011;16:25-9.

25. Bellavia D, Pellikka PA, Abraham TP, Al-Zahrani GB, Dispenzieri A, Oh JK, et al. Evidence of impaired left ventricular systolic function by Doppler myocardial imaging in patients with systemic amyloidosis and no evidence of cardiac involvement by standard two-dimensional and Doppler echocardiography. Am J Cardiol 2008;101:1039-45.

26. Koyama J, Ray-Sequin PA, Falk RH. Longitudinal myocardial function assessed by tissue velocity, strain, and strain rate tissue Doppler echocardiography in patients with al (primary) cardiac amyloidosis. Circulation 2003;107:2446-52.

27. Phelan D, Collier P, Thavendiranathan P, Popovic Z, Hanna M, Plana J, et al. Relative "apical sparing" of longitudinal strain using 2-dimensional speckle-tracking echocardiography is both sensitive and specific for the diagnosis of cardiac amyloidosis. Heart 2012;98:1442-8.

28. Bellavia D, Pellikka PA, Dispenzieri A, Scott CG, Al-Zahrani GB, Grogan M, et al. Comparison of right ventricular longitudinal strain imaging, tricuspid annular plane systolic excursion, and cardiac biomarkers for early diagnosis of cardiac involvement and risk stratification in primary systematic (AL) amyloidosis: A 5year cohort study. Eur Heart J Cardiovasc Imaging 2012;13:680-9.

29. Klein AL, Hatle LK, Taliercio CP, Oh JK, Kyle RA, Gertz MA, et al. Prognostic significance of Doppler measures of diastolic function in cardiac amyloidosis. A Doppler echocardiography study. Circulation 1991;83:808-16.

30. Tei C, Dujardin KS, Hodge DO, Kyle RA, Tajik AJ, Seward JB. Doppler index combining systolic and diastolic myocardial performance: Clinical value in cardiac amyloidosis. J Am Coll Cardiol 1996;28:658-64.

31. Mohty D, Pibarot P, Dumesnil JG, Darodes N, Lavergne D, Echahidi N, et al. Left atrial size is an independent predictor of overall survival in patients with primary systemic amyloidosis. Arch Cardiovasc Dis 2011;104:611-8.

32. Kristen AV, Perz JB, Schonland SO, Hansen A, Hegenbart U, Sack FU, et al. Rapid progression of left ventricular wall thickness predicts mortality in cardiac light-chain amyloidosis. J Heart Lung Transpl 2007;26:1313-9.

33. Bellavia D, Pellikka PA, Al-Zahrani GB, Abraham TP, Dispenzieri A, Miyazaki C, et al. Independent predictors of survival in primary systemic (AL) amyloidosis, including cardiac biomarkers and left ventricular strain imaging: An observational cohort study. J Am Soc Echocardiogr 2010;23:643-52. 
34. Austin BA, Duffy B, Tan C, Rodriguez ER, Starling RC, Desai MY. Comparison of functional status, electrocardiographic, and echocardiographic parameters to mortality in endomyocardialbiopsy proven cardiac amyloidosis. Am J Cardiol 2009;103:142933.

35. Koyama J, Falk RH. Prognostic significance of strain Doppler imaging in light-chain amyloidosis. JACC Cardiovasc Imaging 2010;3:333-42.

36. Buss SJ, Emami M, Mereles D, Korosoglou G, Kristen AV, Voss A, et al. Longitudinal left ventricular function for prediction of survival in systemic light-chain amyloidosis: Incremental value compared with clinical and biochemical markers. J Am Coll Cardiol 2012;60:1067-76

37. Syed IS, Glockner JF, Feng D, Araoz PA, Martinez MW, Edwards $\mathrm{WD}$, et al. Role of cardiac magnetic resonance imaging in the detection of cardiac amyloidosis. JACC Cardiovasc Imaging 2010;3:155-64.

38. Pennell DJ, Maceira AM. Magnetic resonance imaging in cardiac amyloidosis. JACC Cardiovasc Imaging 2009;2:1378-80.

39. Maceira AM, Joshi J, Prasad SK, Moon JC, Perugini E, Harding I, et al. Cardiovascular magnetic resonance in cardiac amyloidosis. Circulation 2005;111:186-93.

40. Minutoli F, Di Bella G, Mazzeo A, Donato R, Russo M, Scribano $\mathrm{E}$, et al. Comparison between $(99 \mathrm{~m}) \mathrm{Tc}$-diphosphonate imaging and MRI with late gadolinium enhancement in evaluating cardiac involvement in patients with transthyretin familial amyloid polyneuropathy. AJR Am J Roentgenol 2013;200:W256-65.

41. Karamitsos TD, Piechnik SK, Banypersad SM, Fontana M, Ntusi NB, Ferreira VM, et al. Noncontrast T1 mapping for the diagnosis of cardiac amyloidosis. JACC Cardiovasc Imaging 2013;6:488-97.

42. Banypersad SM, Sado DM, Flett AS, Gibbs SD, Pinney JH, Maestrini V, et al. Quantification of myocardial extracellular volume fraction in systemic al amyloidosis: An equilibrium contrast cardiovascular magnetic resonance study. Circ Cardiovasc Imaging 2013;6:34-9.

43. Mongeon FP, Jerosch-Herold M, Coelho-Filho OR, Blankstein R, Falk RH, Kwong RY. Quantification of extracellular matrix expansion by CMR in infiltrative heart disease. JACC Cardiovasc Imaging 2012;5:897-907.

44. Wassmuth R, Abdel-Aty H, Bohl S, Schulz-Menger J. Prognostic impact of T2-weighted CMR imaging for cardiac amyloidosis. Eur Radiol 2011;21:1643-50.

45. Dungu J, Whelan CJ, GIbbs S. Patterns of late gadolinium enhancement predict survival in cardiac amyloidosis: A systematic review of 95 cases with al or TTR type. J Am Coll Cardiol 2012;59:1225.

46. Ruberg FL, Appelbaum E, Davidoff R, Ozonoff A, Kissinger KV, Harrigan C, et al. Diagnostic and prognostic utility of cardiovascular magnetic resonance imaging in light-chain cardiac amyloidosis. Am J Cardiol 2009;103:544-9.

47. Mekinian A, Lions C, Leleu X, Duhamel A, Lamblin N, Coiteux $\mathrm{V}$, et al. Prognosis assessment of cardiac involvement in systemic $\mathrm{AL}$ amyloidosis by magnetic resonance imaging. Am J Med 2010;123:864-8

48. Glaudemans AW, Slart RH, Zeebregts CJ, Veltman NC, Tio RA, Hazenberg BP, et al. Nuclear imaging in cardiac amyloidosis. Eur J Nucl Med Mol Imaging 2009;36:702-14.

49. Ng B, Connors LH, Davidoff R, Skinner M, Falk RH. Senile systemic amyloidosis presenting with heart failure: A comparison with light chain-associated amyloidosis. Arch Intern Med 2005;165:1425-9.

50. Hazenberg BP, van Gameren II, Bijzet J, Jager PL, van Rijswijk MH. Diagnostic and therapeutic approach of systemic amyloidosis. Neth J Med 2004;62:121-8.
51. Westermark P, Benson MD, Buxbaum JN, Cohen AS, Frangione $\mathrm{B}$, Ikeda S, et al. Amyloid: Toward terminology clarification. Report from the nomenclature committee of the international society of amyloidosis. Amyloid 2005;12:1-4.

52. Benson MD. The hereditary amyloidoses. Best Pract Res Clin Rheumatol 2003;17:909-27.

53. Rapezzi C, Quarta CC, Guidalotti PL, Longhi S, Pettinato C, Leone $\mathrm{O}$, et al. Usefulness and limitations of ${ }^{99 \mathrm{~m}} \mathrm{Tc}-3,3-$ diphosphono-1,2-propanodicarboxylic acid scintigraphy in the aetiological diagnosis of amyloidotic cardiomyopathy. Eur $\mathrm{J}$ Nucl Med Mol Imaging 2011;38:470-8.

54. Rapezzi C, Quarta CC, Guidalotti PL, Pettinato C, Fanti S, Leone $\mathrm{O}$, et al. Role of (99m)Tc-DPD scintigraphy in diagnosis and prognosis of hereditary transthyretin-related cardiac amyloidosis. JACC Cardiovasc Imaging 2011;4:659-70.

55. Hongo M, Yamada H, Okubo S, Hirayama J, Fujii T, Kusama S, et al. Cardiac involvement in systemic amyloidosis: Myocardial scintigraphic evaluation. J Cardiogr 1985;15:163-80.

56. Bokhari S, Castano A, Pozniakoff T, Deslisle S, Latif F, Maurer MS. (99m)Tc-pyrophosphate scintigraphy for differentiating lightchain cardiac amyloidosis from the transthyretin-related familial and senile cardiac amyloidoses. Circ Cardiovasc Imaging 2013;6:195-201.

57. Perugini E, Guidalotti PL, Salvi F, Cooke RM, Pettinato C, Riva $\mathrm{L}$, et al. Noninvasive etiologic diagnosis of cardiac amyloidosis using ${ }^{99 \mathrm{~m}} \mathrm{Tc}$-3,3-diphosphono-1,2-propanodicarboxylic acid scintigraphy. J Am Coll Cardiol 2005;46:1076-84.

58. Dubrey SW, Cha K, Anderson J, Chamarthi B, Reisinger J, Skinner M, et al. The clinical features of immunoglobulin lightchain (AL) amyloidosis with heart involvement. QJM 1998:91:141-57.

59. Noordzij W, Glaudemans AW, Slart RH, Dierckx RA, Hazenberg BP. Clinical use of differential nuclear medicine modalities in patients with ATTR amyloidosis. Amyloid 2012;19:208-11.

60. Chen W, Dilsizian V. Molecular imaging of amyloidosis: Will the heart be the next target after the brain? Curr Cardiol Rep 2012;14:226-33.

61. Pepys MB, Dyck RF, de Beer FC, Skinner M, Cohen AS. Binding of serum amyloid p-component (SAP) by amyloid fibrils. Clin Exp Immunol 1979;38:284-93.

62. Sobol SM, Brown JM, Bunker SR, Patel J, Lull RJ. Noninvasive diagnosis of cardiac amyloidosis by technetium-99m-pyrophosphate myocardial scintigraphy. Am Heart J 1982;103:563-6.

63. Falk RH, Lee VW, Rubinow A, Hood WB Jr, Cohen AS. Sensitivity of technetium-99m-pyrophosphate scintigraphy in diagnosing cardiac amyloidosis. Am J Cardiol 1983;51:826-30.

64. Gertz MA, Brown ML, Hauser MF, Kyle RA. Utility of technetium Tc 99m pyrophosphate bone scanning in cardiac amyloidosis. Arch Intern Med 1987;147:1039-44.

65. Yamamoto Y, Onoguchi M, Haramoto M, Kodani N, Komatsu A, Kitagaki $\mathrm{H}$, et al. Novel method for quantitative evaluation of cardiac amyloidosis using (201)TlCl and (99m)Tc-PYP SPECT. Ann Nucl Med 2012;26:634-43.

66. Furukawa K, Ikeda S, Okamura N, Tashiro M, Tomita N, Furumoto $\mathrm{S}$, et al. Cardiac positron-emission tomography images with an amyloid-specific tracer in familial transthyretin-related systemic amyloidosis. Circulation 2012;125:556-7.

67. Antoni G, Lubberink M, Estrada S, Axelsson J, Carlson K, Lindsjo $\mathrm{L}$, et al. In vivo visualization of amyloid deposits in the heart with 11c-PIB and PET. J Nucl Med 2013;54:213-20.

68. Wells K, Osborne D, Stuckey A, Wilson S, Wall J, Solomon A. $18 \mathrm{~F}$ florbetapir PET/CT cardiac amyloid imaging in patients with systemic amyloidosis. J Nucl Med 2013;54:294. 